\title{
Vibration resistance of headlamp design with light emitting diodes for electric locomotive
}

\author{
Abulkhanov S.R., Skuratov D.L. \\ Samara State Aerospace University
}

\begin{abstract}
We determined the natural frequencies of the headlight structure with light emitting diodes (LEDs) for electric locomotive (VL series). We used the ANSYS software system of finite-element analysis for computations. The obtained values of the natural frequencies and the oscillation character of the design on every mode made it possible to determine the design activities that increase the vibration resistance of the design of a headlight.
\end{abstract}

Keywords: a headlight of a locomotive, the natural frequencies of the structure, trouble-free service life, periodic vibration, light-emitting diodes (LEDs).

Citation: Abulkhanov SR, Skuratov DL. Vibration resistance of headlamp design with light emitting diodes for electric locomotive. Proceedings of Information Technology and Nanotechnology (ITNT-2015), CEUR Workshop Proceedings, 2015; 1490: 122-132. DOI: 10.18287/1613-0073-2015-1490-122132

\section{Introduction}

The light emitting diodes (LEDs) have several advantages over incandescent lamps, among them are the reliability (MTBF http://www.google.ru/url?source $=$ transpromo $\& \mathrm{rs}=\mathrm{rssf} \& \mathrm{q}=/ /$ translate. google $. \mathrm{com} / \mathrm{community}$ ? source=all - mean time between failures to 1.4 million $\mathrm{H}$ ). The service life (not less 50-103 hours), the viewing angle ( $\phi \subset\left[4^{0}-160^{\circ}\right]$ ), the brightness (up to $15,000 \mathrm{mcd}$ and above) and the energy efficiency (the energy consumption is reduced to $87 \%$ compared to an incandescent lamp) [1 - 2].

The lighting devices with the LED light sources have a number of disadvantages identified during the operation

[http://trainclub.ru/view_blog/svetodiody_na_zheleznodorozhnom_transporte/]:

- apparent signals appearing due to the reflection of the sunlight or light from a searchlight of a locomotive ("phantoms");

- signals with apparent white dots appearing due to the exposure to the direct sunlight ("washouts");

- to provide the desired light flow in industrial light lamps it is necessary to use a large number of the light-emitting diodes. 
These factors indicate that it is impossible to realize all the advantages of the LEDs without considering the peculiarities of their application in a particular industry. So, the lighting devices of general industrial use on the LEDs are not applied, for example, in the rail transport.

For this reason, the research and designs aimed at optimizing the construction of lighting devices using the LED light sources are of great importance. At the same time it should be noted that the Russian railways would like to use the LED lamps as a substitute for the exploited ones, i.e. the existing rail lighting devices have to be modernized as the LED light sources with a minimum number of design changes [http://trainclub.ru/view_blog/svetodiody_na_zheleznodorozhnom_transporte/]. The Railways reflect a global world trend, associated with the modernization of signaling devices used on the railways. For example, the transport administration MTA in New York replaced the light sources in the outdoor traffic lights by the LED light sources, without changing the design of the traffic lights.

Several companies that produce searchlights for a locomotive with the LED light sources are known all over the world, among them are the LEDtronic (Canada), Translight Corp (USA), SBF Spezialleuchten GmbH (Germany) and others. In Russia, the front LED searchlight LPB-01 is designed by the Company SMU "RoSAT" (Armavir) and is produced by the plant-producer "Svetodiod ltd." (St. Petersburg). The powerful original LEDs with the white light serve as the light source. A searchlight LPB-01 has a greater board (the light emitting surface) than a frontal lamp with an incandescent lamp, so as a result, to install it, for example, on the electric locomotive EP1M it's necessary to reconstruct not only a bracket for placing a searchlight in the cab, but also the body of the locomotive cab. This fact increases the cost of modernizing a frontal lamp and does not meet the requirements of the Russian Railways - ensuring a minimum number of the design changes.

A set of regulations with the requirements for locomotive lighting devices is developed with the participation of the Russian Railways. A headlight must provide the nominal axial force of light when achieving the angles of scattering the light beam in the vertical and horizontal planes $\sim 3^{\circ}$ in accordance with Appendix 1 GOST 12.2.056-81. Focusing the searchlight is carried out in this case the following way: a searchlight spaced apart from the screen at $10 \mathrm{~m}$ forms a light spot with the diameter of $1000 \mathrm{~mm}$ on a flat screen perpendicular to the horizon. The nominal axial force of the light in the center of the light spot should be $6.4-9.6 \cdot 10^{5} \mathrm{~cd}$. The light emitting surface of a circular board of the front lamp with LEDs replacing a reflector should have a diameter $370 \mathrm{~mm}$.

When replacing an elliptical reflector and an incandescent lamp in the existing design of a headlight [3] with the board with the LEDs it is possible to preserve the lighting characteristics of a searchlight, without altering the body of a locomotive cab. Simultaneously, the work of a front lamp becomes more reliable, vibration-resistant and economical.

\section{The analysis of the lighting characteristics of a searchlight and the LED light sources}

A searchlight as a light-signal lighting device redistributes the light flow in a small solid angle.

Its diagram of the angular distribution of the light intensity may differ from its own diagram of the light source. In this connection, it is necessary to estimate the 
number and type of the LEDs installed on the board, replacing an incandescent lamp and an elliptical reflector.

The area of a circle, lightened by a headlight, on the shield will be

$S=\frac{\pi \cdot D^{2}}{4}=\frac{\pi \cdot(1000)^{2}}{4}=785375 \mathrm{~mm}^{2}$

Suppose that the design of a searchlight uses 56 LEDs. In this case, one LED has the area $14024.553 \mathrm{~mm} 2$ of the lightened circle on the shield. Since a LED generates the light flow in an axially symmetric solid angle (angle of lightening $\alpha$ ), each of the 56 LEDs should lighten a circle of diameter

$$
D=\sqrt{\frac{4 \cdot S}{\pi}}=\sqrt{\frac{4 \cdot 14024.553}{\pi}}=133.63 \mathrm{~mm}
$$

The indicator LEDs of the brand RL50-WH744D, implemented by "DART Electronics» (http://www.dart.ru/), have a diameter of $5 \mathrm{~mm}$ and generate the white light of the brightness (the light intensity) $8000 \mathrm{mcd}$. We take an angle of lighting $\alpha$ of the LED, equal to 1600 . In this case, the light intensity of $8000 \mathrm{mcd}$ fits the light flow:

$$
F=I \cdot 2 \pi\left(1-\cos \left(\frac{\alpha}{2}\right)\right)=8 \cdot 2 \pi\left(1-\cos \left(\frac{160}{2}\right)\right)=41.537 \mathrm{~lm} \text {, }
$$

where $F$ is the light flow (lm), $I$ is the light intensity (cd), $\alpha$ is an angle of lightening (degrees).

For the LED diameter of $5 \mathrm{~mm}$, the distance to the shield of 10 meters and the diameter of the circle lightened by one LED on the board $133 \mathrm{~mm}$ the angle of lightening will be $\alpha=2 \cdot \theta 0,73^{\circ}$. Here $\theta$ is an angle of half brightness.

The redistribution in the space of the light flow generated by a LED, is performed by the selection of elements of the secondary optics, which are intended to create a smooth spot of the exposure with the right diagram of dissipation. Thus, a collimator of the secondary optics is the required structural element of a headlight with the LED light sources. In the case of using the secondary optics for the LEDs developed at IPSI RAS [4 - 16], the generated light flow can be directed practically with no loss in the axial symmetric solid angle of 0.730 . In this case, the light intensity will be of the amount:

$$
I=\frac{F}{2 \pi\left(1-\cos \left(\frac{\alpha}{2}\right)\right)}=\frac{41.537}{2 \pi\left(1-\cos \left(\frac{0.73}{2}\right)\right)}=325780.392 \mathrm{~cd} .
$$

For 56 LEDs the power of light on the lighted circle of the shield may be on the axis of symmetry (the interference is not taken into account)

$I_{\Sigma}=325780 \mathrm{~cd} \cdot 56=18243680 \mathrm{~cd} \approx 18.245 \cdot 10^{6} \mathrm{~cd}$.

An incandescent lamp SL 5-500, of the power 500-watt used as a light source of a headlight with an elliptical reflector with a diameter of $370 \mathrm{~mm} \mathrm{[3],} \mathrm{generates} \mathrm{the}$ light flow of $11100 \mathrm{~lm}$ according to the technical certificate.

From the requirements of Annex 1 it can be determined that the angle of lightening $\alpha$ on the shield of the circle with a diameter of $1000 \mathrm{~mm}$ is equal to $\alpha=2 \cdot \theta$ $=3.6^{\circ}$. The light intensity in this case is equal (for $\alpha=3.6^{\circ}$ )

$I=\frac{F}{2 \pi\left(1-\cos \left(\frac{\alpha}{2}\right)\right)}=\frac{11100}{2 \pi\left(1-\cos \left(\frac{3.6}{2}\right)\right)}=3533343.9 \mathrm{~cd} \approx 3.5 \cdot 10^{6} \mathrm{~cd}$. 
The light parameters of an incandescent lamp and the LEDs, as well as the requirements to the light source, regulated by GOST 12.2.056-81 are summarized in Table 1.

Table 1. The lighting characteristics of different light sources

\begin{tabular}{|l|l|l|l|l|l|l|l|}
\hline № & $\begin{array}{l}\text { Type of light } \\
\text { source }\end{array}$ & $\begin{array}{l}\text { Power, } \\
\text { W }\end{array}$ & Amount & $\begin{array}{l}\text { Light without } \\
\text { optics, lx }\end{array}$ & Used optics & $\begin{array}{l}\text { Angle of light, } \\
\text { formed } \\
\text { optics }\end{array}$ & $\begin{array}{l}\text { Light } \\
\text { intensity, cd }\end{array}$ \\
\hline 1 & $\begin{array}{l}\text { Incandescent } \\
\text { lamp, SL } \\
\text { 5-500 }\end{array}$ & 500 & 1 & 11100 & $\begin{array}{l}\text { Elliptical reflector } \\
\text { with diameter } 370 \\
\text { mm }\end{array}$ & $0.73^{0}$ & $3.5 \cdot 10^{6}$ \\
\hline 2 & $\begin{array}{l}\text { Signal LED, } \\
\text { brand RL50- } \\
\text { WH744D }\end{array}$ & 0.06 & 56 & 41.537 & $\begin{array}{l}\text { Secondary optics } \\
\text { (collimator) } \\
\text { [4-16] }\end{array}$ & $3.6^{0}$ & $18.245 \cdot 10^{6}$ \\
\hline 3 & $\begin{array}{l}\text { The intensity of light recommended in Appendix GOST 12.2.056-81. «The System of standards of } \\
\text { labor safety. Electric and diesel locomotives of track 1520 mm» }\end{array}$ & $6.4-9.6 \cdot 10^{5}$ \\
\hline
\end{tabular}

The table shows that in order to achieve the light intensity required by the regulatory documents it is possible to use a smaller number of the LEDs or (and) a collimator [4 - 16] of a greater angle of lighting, that is $\alpha=2 \cdot \theta>0.73^{\circ}$.

The heat is produced in the semiconductor junction of the crystal LED, and the high-power LEDs have the magnitude of the heat, that is sufficient to change the characteristics of the LED light source. The installing armature of the LED made of materials with the high thermal conductivity (typically aluminum alloy) is made for the effective heat dissipation of the LED. The thermal deformation of the structure of the lighting device is capable of changing the diagram of the angular distribution of the light intensity generated by the LEDs. Using the design of a searchlight of a locomotive as light sources indicating LEDs, we can ignore the thermal deformation of the board with the LEDs.

To ensure the required diagram of the angular distribution of the light intensity, we use the matrix (block) system of the light sources arranged on the board (the light emitting surface) of a searchlight in accordance with the interstate standards "Occupational safety of labor standards system. Electric and diesel locomotives with the rail track of $1520 \mathrm{~mm}$. Safety requirements." From the technological considerations the placement of the LEDs on the board evenly on the coaxial circles is most appropriate. The radii of the adjacent circles differ in one value.

As an original model of a headlight of a locomotive weighing $17.438 \mathrm{~kg}$, a model of a searchlight with an incandescent lamp and an elliptical reflector is used [3], in which a reflector and the installing armature of an incandescent lamp have been removed, and instead, a disk, made of the aluminum alloy D16T of the thickness of 3 $\mathrm{mm}$ and a diameter $370 \mathrm{~mm}$, is installed, on which the LEDs are installed (Fig. 1).

Two lugs made of aluminum alloy D16T are welded on the disk. As the LED light source a model of the LED SMD 3528-W produced by the firm CIVILIGHT (Taiwan) is used (Fig. 2), generating the white light and is analogous to the indicator LED of the brand RL50-WH744D, the characteristics of which are used in the calculations. An LED 1 is installed in the special armature, consisting of an aluminum base 2 , which is installed in a ceramic conductor 3 , centering the lens of the secondary optics 4 (Fig. 2). 


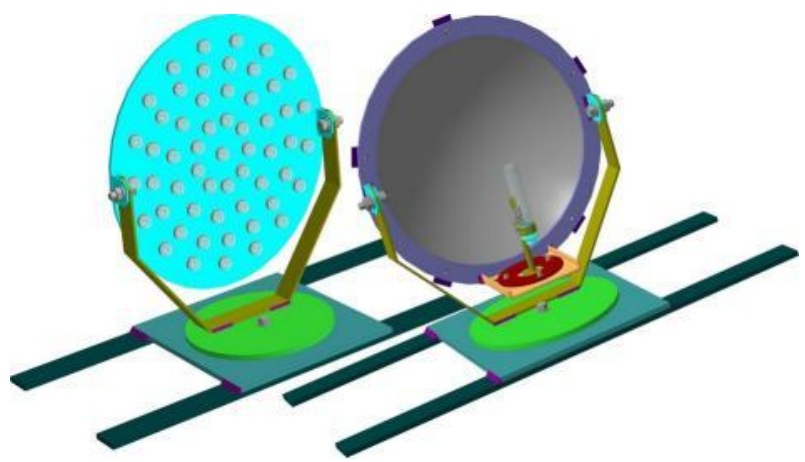

Fig. 1. - A headlight of a locomotive with the LED light sources and with an incandescent lamp.

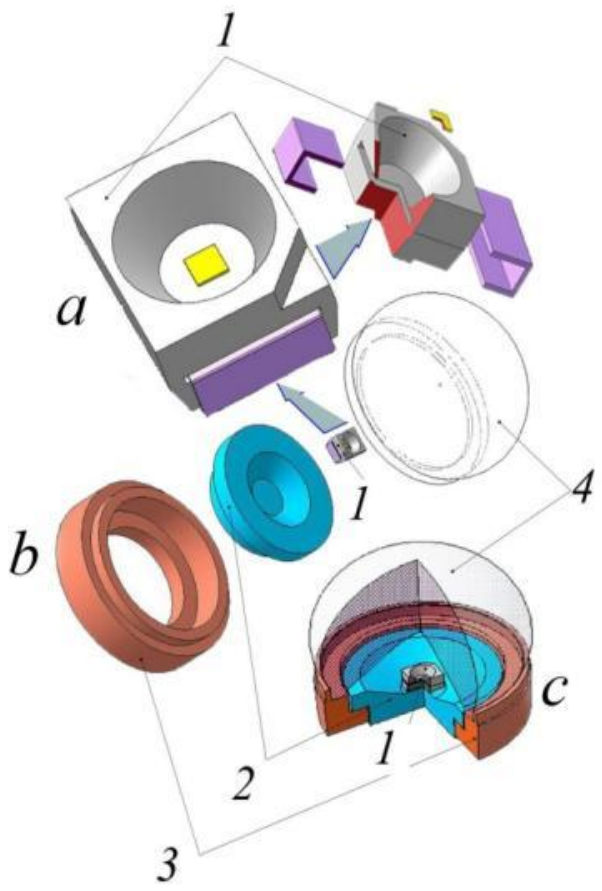

Fig. 2. - The LED light source: a - the design of the LED; $b$ - the armature of the LED construction; $\mathrm{c}$ - the assembly of the structure of the LED light source.

\section{The vibration resistance of the modernized design of a searchlight}

The modification of the design of a searchlight results in changing the natural frequencies of the lighting device, the values of which can lead to the resonance of the whole structure during the operation of a railway locomotive [17-19]. For this reason, it is necessary first to determine the natural frequencies of the modified design 
of a searchlight and, if necessary, to provide measures that increase the vibration resistance of the design of a locomotive frontal lamp.

Table 2 summarizes the weights and elastic characteristics of the elements of a searchlight, removed from the construction, and the elements included in the design. Table 2 shows that the weight of the structure of the modernized searchlight is $18.725 \mathrm{~kg}$, i. e. it increased by $1.287 \mathrm{~kg}$ or $7.4 \%$. This fact indicates the possibility of optimizing the design of the board, that can be performed with the holes making it easier and optimizing the number of LEDs. The control of the weight of a searchlight allows you to change the natural frequency of its design, and thus to influence the vibration resistance of a headlight.

To determine the natural frequencies of the modernized design of a searchlight we use the software that runs on the platform of ANSYS Workbench.

The model does not take into account the threaded connections used in the actual design. Fig. 3 shows the layout of a model into finite elements.

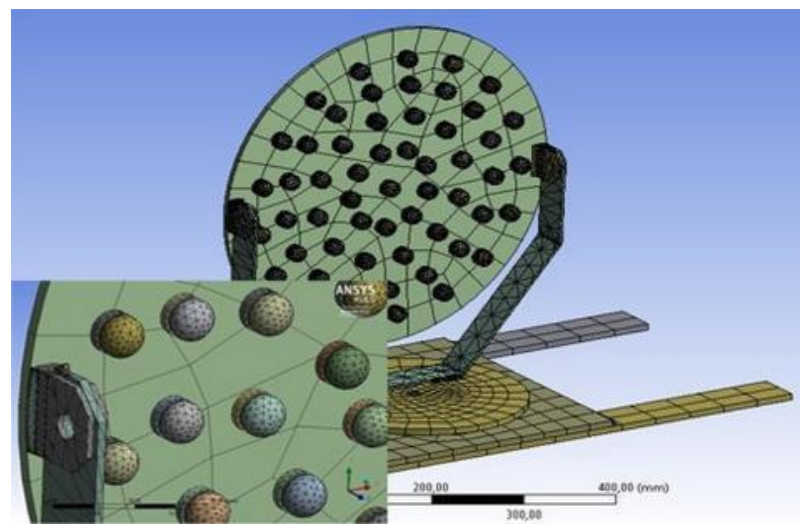

Fig. 3. - The layout of the model of a front lamp with the LED light sources.

Fig. 3 shows the deformation of the design of a searchlight on the first six natural frequencies of the design. Fig. 4 shows that the aluminum board experiences the significant deformation at different frequencies, which may occur during the movement of the locomotive [18]. In addition, the posts supporting the board, is also experiencing the considerable deformation. Both of these circumstances indicate that the design of the board and post should be reinforced with the gussets and rigidity edges, such as in Fig. 5. The weight of the design of a searchlight should not be increased in comparison with the front lamp with an incandescent lamp as the light source. In addition to the full range of vibration frequencies that can occur when operating a railway locomotive [18], a searchlight has to ensure the creation of a stable smooth spot of the exposure with the right diagram of scattering. Solving such complex problems is only possible in case of the construction of a parametric model of a head-lamp, establishing the criteria of the optimization of a model and its geometry parameters in the software environment of ANSYS. 
a)

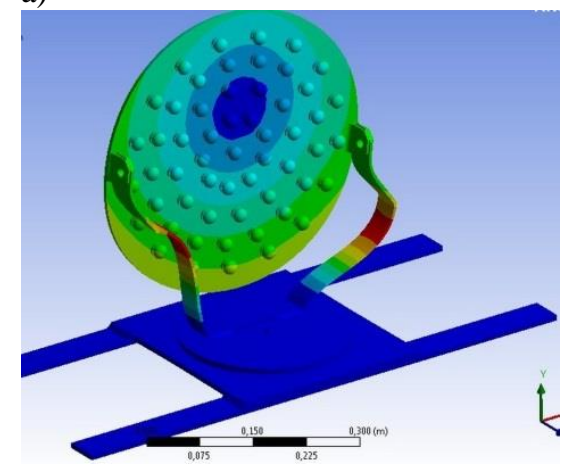

b)

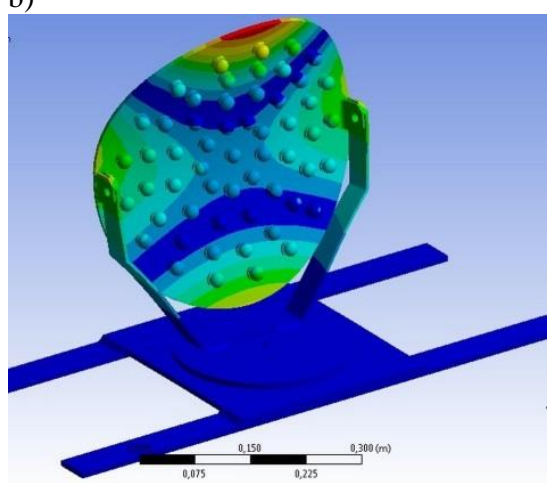

c)

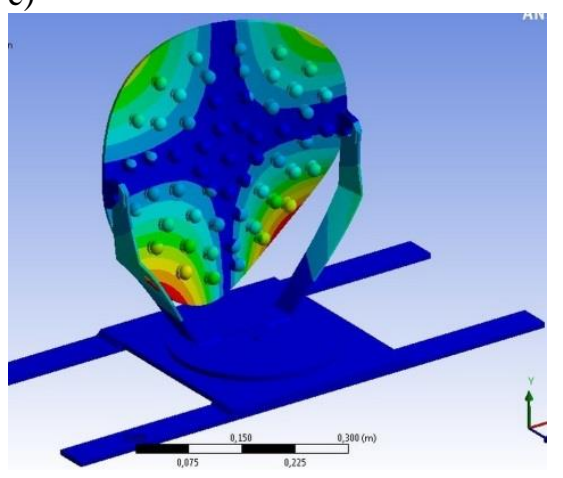

d)

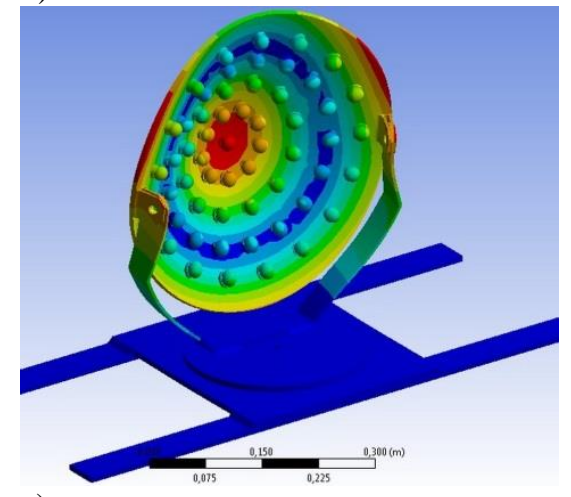

e)

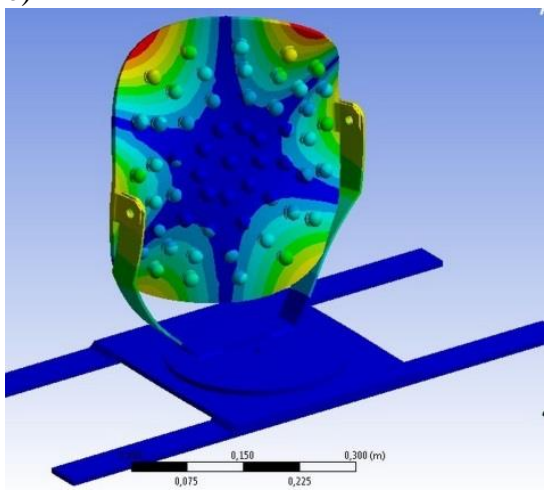

g)

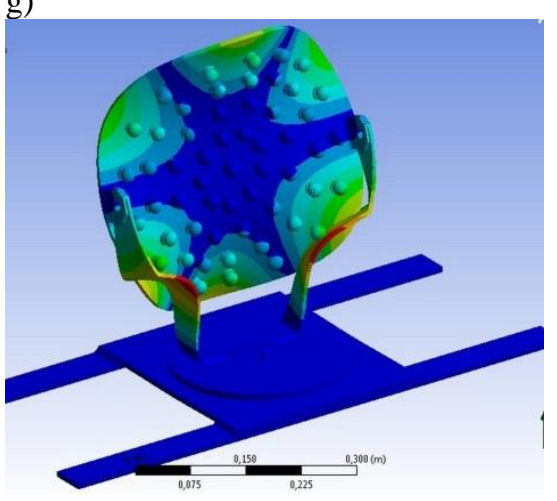

Fig. 4. - The deformations of the design of a headlight with the LED light sources in various modes: a) $f=202.43 \mathrm{~Hz}$; b) $f=231.22 \mathrm{~Hz}$; c) $f=292.39 \mathrm{~Hz}$; d) $f=202.43 \mathrm{~Hz}$; e) $f=393.42 \mathrm{~Hz}$; g) $f=439.08 \mathrm{~Hz}$ 


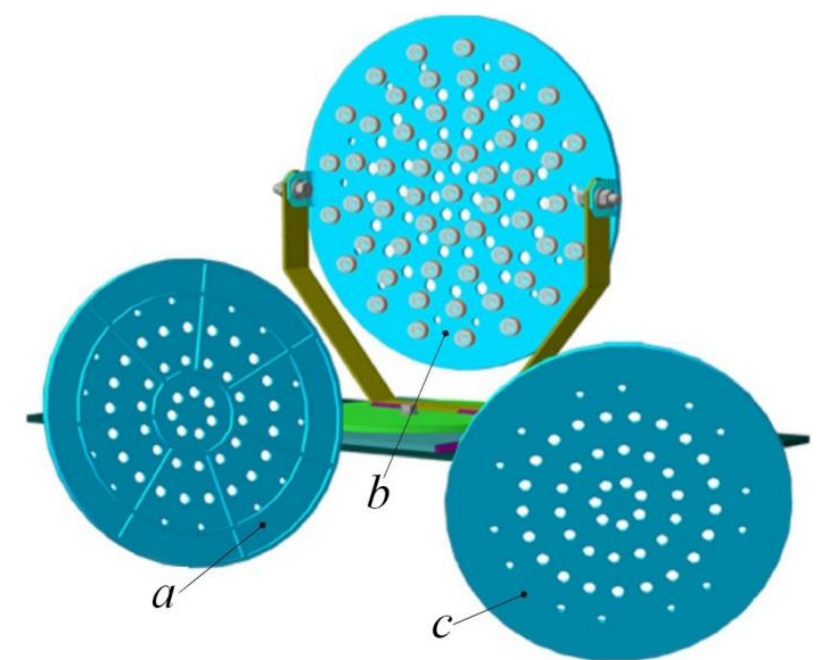

Fig. 5. - The design of the board for the LEDs: a - a rear view of the board; $b$ - the assembly of a searchlight with the modernized board; $\mathrm{c}$ - full face of the board

Table 2. Weight and elastic characteristics of the elements of the headlight design

\begin{tabular}{|c|c|c|c|c|c|c|}
\hline № & Part Name & Amount & Material & $\begin{array}{l}\text { Weight of } \\
\text { a unit, kg }\end{array}$ & $\begin{array}{l}\text { volume of }{ }^{3} \text { a } \\
\text { unit, } 10^{-6} \mathrm{~m}^{3}\end{array}$ & $\begin{array}{l}\text { Total } \\
\text { Weight, kg }\end{array}$ \\
\hline \multicolumn{7}{|c|}{ Components of a searchlight with an incandescent lamp, removed from the construction } \\
\hline 1 & Reflector & 1 & glass & 0.603 & 270.279 & 0.603 \\
\hline 2 & E / Lamp & 1 & - & 0.105 & 78.242 & 0.105 \\
\hline 3 & E / Lamp socket & 1 & Carbolite & 0.032 & 7.485 & 0.032 \\
\hline 4 & Post & 1 & \multirow{10}{*}{ St. $20 \mathrm{G}$} & 0.969 & 123.967 & 0.969 \\
\hline 5 & Lug & 2 & & 0.077 & 9.869 & 0.154 \\
\hline 6 & Flange & 1 & & 0.172 & 219.757 & 0.172 \\
\hline 7 & Plank & 1 & & 0.552 & 70.646 & 0.552 \\
\hline 8 & Bolt shaped & 1 & & 0.178 & 22.711 & 0.178 \\
\hline 9 & Disk & 1 & & 0.212 & 27.148 & 0.212 \\
\hline 10 & Base & 1 & & 6.189 & 791.371 & 6.189 \\
\hline 11 & Strip & 2 & & 2.502 & 320.0 & 5.005 \\
\hline 12 & Holder & 5 & & 0.017 & 2.202 & 0.086 \\
\hline 13 & Brackets & 2 & & 0.019 & 2.372 & 0.037 \\
\hline 14 & Rubber gasket & 5 & C/rubber & $\leq 0.005$ & 4.058 & $\leq 0.026$ \\
\hline 15 & Weld & - & $\begin{array}{l}\text { St. } 60 \mathrm{C} 2 \mathrm{~A} ; \\
65 \mathrm{C} 2 \mathrm{BA}\end{array}$ & 2.566 & 330.457 & 2.566 \\
\hline \multicolumn{7}{|c|}{ New and modernized components of the design of a searchlight } \\
\hline 1 & Flange $(\mathrm{h}=3 \mathrm{~mm})$ & 1 & D16T & 2.303 & 831.265 & 2.303 \\
\hline 2 & Lug & 2 & D16T & 0.027 & 9.869 & 0.054 \\
\hline 3 & $\begin{array}{l}\text { Diffuser } \\
\text { optics) }\end{array}$ (of $\quad$ secondary & 57 & $\begin{array}{ll}\text { Plexiglas } & \text { or } \\
\text { polymethyl } \\
\text { methacrylate }\end{array}$ & 0.012 & 2.715 & 0.684 \\
\hline 4 & Contact plate & 114 & Copper & $0.8 \times 10^{-5}$ & $\approx 0.001$ & $10^{-3}$ \\
\hline 5 & Light-emitting plate & \multirow{4}{*}{57} & \multirow{3}{*}{$\begin{array}{l}\text { Alumina } \\
\left(\mathrm{Al}_{2} \mathrm{O}_{3}\right) \text { and } \\
\text { alumino-nitride } \\
(\mathrm{AlN}) \text { ceramics }\end{array}$} & $0.02 \times 10^{-5}$ & 0.0005 & $\approx 10^{-5}$ \\
\hline 6 & LED housing & & & $0.41 \times 10^{-5}$ & 0.011 & $0.2 \times 10^{-3}$ \\
\hline 7 & $\begin{array}{l}\begin{array}{l}\text { Conductor of LED light } \\
\text { source }\end{array} \\
\end{array}$ & & & $3.5 \times 10^{-3}$ & 0.536 & 0.2 \\
\hline 8 & Base of LED light source & & $\mathrm{D} 16 \mathrm{~T}$ & $0.004 \times 10^{-3}$ & 1.273 & 0.257 \\
\hline
\end{tabular}




\section{Conclusions:}

1. The indicator LEDs can be used in the headlight of a locomotive to provide the required lighting characteristics.

2. The indicator LEDs should be equipped with the original secondary optics.

3. The construction of a headlight with the LED light source should include the design activities, raising its vibration resistance.

4. It is possible to optimize the design of a headlight, taking into account all the regulatory requirements only if there is a parametric model.

5. The presented results play an important role in the design [20-25] of hyperspectral remote sensing equipment feeling strong vibrations loads in the derivation of Earth's orbit. Also, these results will be useful for creating transport systems of computer vision [26-29], optical devices [30-33], components, and devices of diffractive nanophotonics [34-40].

\section{References}

1. Moiseev MA, Doskolovich LL, Kazanskiy NL. Design of high-efficient freeform LED lens for illumination of elongated rectangular regions. Optics Express, 2011; 19(S3): A225-233.

2. Aslanov ER, Doskolovich LL, Moiseev MA, Bezus EA, Kazanskiy NL. Design of an optical element forming an axial line segment for efficient LED lighting systems. Optics Express, 2013; 21(23): 28651-28656.

3. Abulkhanov SR. Construction of authentic 3-D model of head-lamp of electric locomotive VL series. Vestnik Samara State University of Communications, 2012; 3(17): 81-86. [in Russian]

4. Golub MA, Kazanskii NL, Sisakyan IN, Soifer VA. Computational experiment with plane optical elements. Optoelectronics, Instrumentation and Data Processing, 1988; 1: 7889.

5. Golub MA, Kazanskii NL, Sisakyan IN, Soifer VA, Kharitonov SI. Diffraction calculation for an optical element which focuses into a ring. Optoelectronics, Instrumentation and Data Processing, 1987; 6: 7-14.

6. Kazanskiy NL, Kotlyar VV, Soifer VA. Computer-aided design of diffractive optical elements. Optical Engineering, 1994; 33(10): 3156-3166.

7. Kazanskiy NL, Soifer VA. Diffraction investigation of geometric-optical focusators into segment. Optik International Journal for Light and Electron Optics, 1994; 96(4): 158-162.

8. Doskolovich LL, Kazansky NL, Kharitonov SI, Soifer VA. A method of designing diffractive optical elements focusing into plane areas. Journal of Modern Optics, 1996; 43(7): 1423-1433.

9. Doskolovich LL, Kazanskiy NL, Bernard S. Designing a mirror to form a line-shaped directivity diagram. Journal of Modern Optics, 2007; 54(4): 589-597.

10. Doskolovich LL, Kazanskiy NL, Soifer VA, Kharitonov SI, Perlo P. A DOE to form a line-shaped directivity diagram. Journal of Modern Optics, 2004; 51(13): 1999-2005.

11. Doskolovich LL, Kazanskiy NL, Soifer VA, Perlo P, Repetto P. Design of DOEs for wavelength division and focusing. Journal of Modern Optics, 2005; 52(6): 917-926. doi:10.1080/09500340512331313953.

12. Doskolovich LL, Golub MA, Kazanskiy NL, Khramov AG, Pavelyev VS, Seraphimovich PG, Soifer VA, Volotovskiy SG. Software on diffractive optics and computer generated holograms. Proceedings of SPIE, 1995; 2363: 278-284. 
13. Doskolovich LL, Kazanskiy NL, Soifer VA, Tzaregorodtzev AYe. Analysis of quasiperiodic and geometric optical solutions of the problem of focusing into an axial segment. Optik - International Journal for Light and Electron Optics, 1995; 101(2): 37-41.

14. Khonina SN, Kazanskiy NL, Volotovsky SG. Influence of Vortex Transmission Phase Function on Intensity Distribution in the Focal Area of High-Aperture Focusing System. Optical Memory and Neural Networks (Information Optics), 2011; 20(1): 23-42. doi: 10.3103/S1060992X11010024.

15. Golovashkin DL, Kasanskiy NL. Solving Diffractive Optics Problem using Graphics Processing Units. Optical Memory and Neural Networks (Information Optics), 2011; 20(2): 85-89. doi: 10.3103/S1060992X11020019.

16. Kazanskiy NL. Research \& Education Center of Diffractive Optics. Proceedings of SPIE, 2012; 8410: 84100R. doi:10.1117/12.923233.

17. Kazanskiy N, Skidanov R. Binary beam splitter. Applied Optics, 2012; 51(14): 2672-2677. doi: 10.1364/AO.51.002672.

18. Doskolovich LL, Dmitriev AYu, Moiseev MA, Kazanskiy NL. Analytical design of refractive optical elements generating one-parameter intensity distributions. J. Opt. Soc. Am. A, 2014; 31(11): 2538-2544. doi: 10.1364/JOSAA.31.002538.

19. Abulkhanov SR, Gorjainov DS, Skuratov DL. Optimization of strength characteristics of aircraft lighting devices by building their virtual models. Bulletin of Samara State Aerospace University, 2012; 5(36). Part 1: 72-78. [in Russian]

20. Abulkhanov SR, Lopatin EV. Vibration resistance of design of frontal lamp of electric locomotive VL series. Bulletin of Volga Transport, 2013; 6(42): 30-36. [in Russian]

21. Karpeev SV, Pavelyev VS, Khonina SN, Kazanskiy NL, Gavrilov AV, Eropolov VA. Fibre sensors based on transverse mode selection. Journal of Modern Optics, 2007; 54(6): 833-844. doi: 10.1080/09500340601066125.

22. Kazanskiy NL, Kharitonov SI, Khonina SN, Volotovskiy SG, Strelkov YuS. Simulation of hyperspectrometer on spectral linear variable filters. Computer Optics, 2014; 38(2): 256-270. [in Russian]

23. Kazanskiy NL, Kharitonov SI, Karsakov AV, Khonina SN. Modeling action of a hyperspectrometer based on the Offner scheme within geometric optics. Computer Optics, 2014; 38(2): 271-280. [in Russian]

24. Kazanskiy NL, Kharitonov SI, Khonina SN. Simulation of a hyperspectrometer based on linear spectral filters using vector Bessel beams. Computer Optics, 2014; 38(4): 770776. [in Russian]

25. Kazanskiy NL, Kharitonov SI, Doskolovich LL, Pavelyev AV. Modeling the performance of a spaceborne hyperspectrometer based on the Offner scheme. Computer Optics, 2015; 39(1): 70-76. [in Russian]

26. Kazanskiy NL, Popov SB. Machine Vision System for Singularity Detection in Monitoring the Long Process. Optical Memory and Neural Networks (Information Optics), 2010; 19(1): 23-30. doi:10.3103/S1060992X10010042.

27. Kazanskiy NL, Popov SB. The distributed vision system of the registration of the railway train. Computer Optics, 2012; 36(3): 419-428. [in Russian]

28. Kazanskii NL, Khonina SN, Skidanov RV, Morozov AA, Kharitonov SI, Volotovskiy SG. Formation of images using multilevel diffractive lens. Computer Optics, 2014; 38(3): 425-434. [in Russian]

29. Kazanskiy NL, Popov SB. Integrated Design Technology for Computer Vision Systems in Railway Transportation. Pattern Recognition and Image Analysis, 2015; 25(2): 215-219. doi: $10.1134 / \mathrm{S} 1054661815020133$. 
30. Khonina SN, Kazanskii NL, Ustinov AV, Volotovskii SG. The lensacon: nonparaxial effects. Journal of Optical Technology, 2011; 78(11): 724-729. doi: 10.1364/JOT.78.000724.

31. Doskolovich LL, Kazanskiy NL, Khonina SN, Skidanov RV, Heikkila N, Siitonen S, Turunen J. Design and investigation of color separation diffraction gratings. Applied Optics, 2007; 46(15): 2825-2830.

32. Borodin SA, Volkov AV, Kazanskii NL. Device for analyzing nanoroughness and contamination on a substrate from the dynamic state of a liquid drop deposited on its surface. Journal of Optical Technology, 2009; 767: 408-412.

33. Khonina SN, Savelyev DA, Kazanskiy NL. Vortex phase elements as detectors of polarization state. Optics Express, 2015; 23(14): 17845-17859. doi: 10.1364/OE.23.017845.

34. Kazanskiy NL, Serafimovich PG, Khonina SN. Harnessing the Guided-Mode Resonance to Design Nanooptical Transmission Spectral Filters. Optical Memory and Neural Networks (Information Optics), 2010; 19(4): 318-324. doi: 10.3103/S1060992X10040090.

35. Bezus EA, Doskolovich LL, Kazanskiy NL. Scattering suppression in plasmonic optics using a simple two-layer dielectric structure. Applied Physics Letters, 2011; 98(22): 221108. doi: 10.1063/1.3597620.

36. Bezus EA, Doskolovich LL, Kazanskiy NL, Soifer VA. Scattering in elements of plasmon optics suppressed by two-layer dielectric structures. Technical Physics Letters, 2011; 37(12): 1091-1095.

37. Kazanskiy NL, Serafimovich PG, Khonina SN. Use of photonic crystal cavities for temporal differentiation of optical signals. Optics Letters, 2013; 38(7): 1149-1151.

38. Kazanskiy NL, Serafimovich PG. Cloud Computing for Nanophotonic Simulations. Lecture Notes in Computer Science, 2013; 7715: 54-67.

39. Bezus EA, Doskolovich LL, Kazanskiy NL. Low-scattering surface plasmon refraction with isotropic materials. Optics Express, 2014; 22(11): 13547-13554. doi: 10.1364/OE.22.013547.

40. Kazanskiy NL, Serafimovich PG. Coupled-resonator optical wave-guides for temporal integration of optical signals. Optics Express, 2014; 22(11): 14004-14013. doi: 10.1364/OE.22.014004. 